\title{
CONFLITOS ÉTICOS VIVENCIADO PELO ENFERMEIRO NO CENTRO CIRÚRGICO FRENTE A TOMADA DE DECISÃO.
}

\author{
Deborah Soares Assis ${ }^{1}$; Elaine Guedes Fontoura; Marluce Alves Nunes Oliveira ${ }^{3}$ \\ 1. Bolsista PIBIC/CNPq, Graduando em Enfermagem, Universidade Estadual de Feira de Santana, e-mail: \\ deborahsoaresassisdsa@gmail.com.br \\ 2. Orientador, Departamento DSAU, Universidade Estadual de Feira de Santana, e-mail: elaineguedesfont@uol.com.br \\ 3. Coordenadora do projeto Vivências de conflitos e dilemas éticos na percepção da equipe de enfermagem no centro \\ cirúrgico, Departamento DSAU, Universidade Estadual de Feira de Santana, e-mail: milicialves@yahoo.com.br
}

PALAVRAS-CHAVE: Ética; Enfermeiro; Tomada de decisões.

\section{INTRODUÇÃO}

A ética acompanha a sociedade há vários séculos, promovendo momentos de reflexão, e, trazendo para sociedade novas formas de pensar as ações humanas. Figueiredo (2008), a ética como uma ciência prática que trata de atos práticos e por isso ela possibilita a promoção de reflexões filosóficas sobre a conduta do ser humano. De acordo com Lacerda (2014, p. 18), "agir eticamente significa nortear as ações humanas para com o mundo e para com tudo que nele existe, com valores e a moral que o indivíduo adquiriu no seu processo evolutivo, em uma sociedade ou grupo de formação". Na prática dos profissionais da equipe de enfermagem no Centro Cirúrgico (CC), especialmente os enfermeiros, podem vivenciar conflitos éticos ao tomarem decisões que tenham relações com paciente, família, bem como com a equipe cirúrgica. Percebe-se que a relação entre a equipe cirúrgica pode torna-se conflituosa a partir do momento que não se chega ao consenso diante as situações que envolvam escassez de recursos humanos e materiais, estrutura física inadequada e uma demanda maior do que o CC pode oferecer.

Para Oliveira e Santa Rosa (2014), para a tomada de decisão faz-se necessárias à competência ética, científica e técnica; estabelecer comunicação eficaz com os profissionais da equipe cirúrgica, paciente e familiares; ter equilíbrio emocional; respeitar à opinião dos profissionais da equipe cirúrgica; buscar estratégias para amenizar as relações; respeitar as crenças dos pacientes; exercer suas funções com autonomia, dentre outros.

Compreende-se a necessidade de os enfermeiros se interrogarem e que façam uma reflexão sobre o agir, com vista a uma tomada de decisões responsáveis diante aos conflitos éticos que emergem no CC. Após realização de leitura reflexiva sobre a temática da ética, ficou clara a necessidade de estudos que evidenciem essa problemática no contexto do $\mathrm{CC}$, no sentido de contribuir com a decisão frente aos conflitos éticos vividos pelos enfermeiros. Diante do exposto estabeleceu-se como questão de pesquisa: Como os enfermeiros tomam decisão frente aos conflitos éticos no CC?

Objetivou compreender a tomada de decisão dos enfermeiros frente aos conflitos éticos no centro cirúrgico. O estudo permitiu conhecer a postura do enfermeiro frente aos conflitos éticos vivenciados no CC, e possibilitou a compreensão de suas atribuições diante de situações que necessite de uma deliberação, ajudando na escolha de posturas éticas e no desenvolvimento das habilidades para a tomada de decisão.

\section{METODOLOGIA}

Trata-se de uma pesquisa exploratória, descritiva com abordagem qualitativa, por trabalhar com um universo de significados e oferecer oportunidade ao pesquisador para compreender e explorar as questões relacionadas à sua prática. $\mathrm{O}$ objeto desta pesquisa é compreender a tomada de decisão do enfermeiro frente aos conflitos éticos no CC. Este estudo está inserido no projeto VIVÊNCIAS DE CONFLITOS E DILEMAS ÉTICOS NA PERCEPÇÃO DA EQUIPE ENFERMAGEM NO CENTRO CIRÚRGICO. As informações 
foram coletadas em agosto e setembro de 2016, por meio de entrevista semiestruturada, em uma unidade de CC de um hospital geral público, de grande porte, localizado no município de Feira de Santana-BA. O primeiro contato foi com a enfermeira coordenadora do CC, que possibilitou o acesso aos enfermeiros. Os participantes da pesquisa foram 5 enfermeiros que atuam no $\mathrm{CC}$, há mais de um ano, que estavam trabalhando e que aceitaram participar da pesquisa, e foram caracterizados como Enf. 01, Enf. 02, Enf. 03, Enf. 04 e Enf. 05 de acordo a ordem de entrevista. Antes de cada entrevista foi lido o Termo de Consentimento Livre e Esclarecido (TCLE), em concordância de participar do estudo e em seguida assinado em duas vias, uma ficou o participante da pesquisa e a outra com a pesquisadora. As entrevistas foram agendadas e efetuadas individualmente, em horários e locais sugeridos pelos próprios participantes. Tendo duas questões norteadoras: Qual a sua compreensão sobre conflito ético? Fale-me como toma decisão frente ao conflito ético vivenciado no CC. Para a concretização do processo de análise foi utilizado análise de conteúdo de Bardin como modo de revelar a síntese da estrutura das categorias empíricas. A análise de conteúdo é um "conjunto de técnicas de análise das comunicações". (Bardin, 2011, p. 37). O estudo se propõe a compreender como o enfermeiro toma decisão frente aos conflitos éticos vivenciados no CC. O projeto foi submetido ao Comitê de Ética em Pesquisa da UEFS, sob protocolo $696.101 \mathrm{em}$ 31/03/2016. Os procedimentos adotados na pesquisa estão em conformidade com as orientações éticas previstas na Resolução 466/12, do Conselho Nacional de Saúde (Brasil, 2012).

\section{RESULTADOS E DISCUSSÃO}

Foram entrevistados 05 enfermeiros que atuam no $\mathrm{CC}$ há mais de um ano. Dentre os 05 entrevistados, 02 do sexo masculino e 03 do sexo feminino. A profissional com maior tempo de formação tem 15 anos de formada e a com menor tempo de formação 06 anos, sendo que com relação ao tempo de atuação no $\mathrm{CC}$ variou de 08 a 02 anos, 4 deles possuem outros vínculos empregatícios e 01 não possui outros vínculos, 04 tem especialização. Após a análise das entrevistas emergiram três categorias: Categoria I Compreensão do conflito ético: os conflitos são provocados por divergências entre a equipe do $\mathrm{CC}$, onde os mesmos deparam-se com alternativas distintas que necessitam de escolhas. Os relatos desvelam a compreensão que os enfermeiros têm sobre os conflitos éticos vivenciados no CC. O CC por ser um ambiente dinâmico exige constantes escolhas diante de situação éticas, visto que a equipe cirúrgica possuem interesses distintos gerando os conflitos. Subcategoria I Embate/ divergências entre profissionais: Os conflitos estão relacionados com embates entre os profissionais da equipe cirúrgica, pois existem profissionais de áreas diferenciadas, preocupando-se com os seus interesses. No ambiente hospitalar, as equipes são compostas por profissionais de formações, entendimentos e interesses diferentes, que apresentam valores, atitudes e crenças divergentes, por esses motivos surgem os conflitos. Os conflitos pertencem a realidade dos seres humanos, podem advir da diferença de valores e vaidades entre pessoas, equipe de trabalho e sociedades Bruinsma et al. (2017). Subcategoria II Conflitos exige escolhas: Mediante a uma situação de conflito é necessário uma escolha, sendo indispensável que sejam respeitados, os princípios éticos, prioridades dos pacientes, analisando as possibilidades, mantendo a calma e dessa forma tomando a melhor decisão, para que sejam resolvidos os conflitos. Frente aos procedimentos realizados no $\mathrm{CC}$, os enfermeiros vivenciam conflitos por estarem diante de possibilidade distintas e pelo ambiente do CC ser dinâmico que atende a procedimentos complexo exigindo dos mesmos escolhas rápidas, a fim de evitar danos ao paciente. Para que os procedimentos sejam realizados de forma efetiva e eficaz, evidencia-se a necessidade de um comportamento que priorize a ética, uma gestão participativa e interativa da equipe multidisciplinar, que valorize o envolvimento de seus membros. É importante pensar em um modelo da prática profissional de enfermagem, 
caracterizado por estrutura, processos e valores, que instrumentalizam o enfermeiro durante a prestação dos cuidados Maurício et al. (2017). Categoria II O conflito ético emergem frente a: Os relatos demonstram que os profissionais de enfermagem vêem que os conflitos surgem e que frente ao mesmo é necessário uma tomada de decisão sendo necessário uma intervenção. Subcategoria I Situações não éticas: Os conflitos surgem quando os princípios éticos não são respeitados, é entendido como tudo aquilo que diverge do que é correto, para a resolução desses conflitos é necessário a articulação da equipe do CC para a construção de ideais que possam contemplar a equipe cirúrgica e o paciente. A resolução dos conflitos pode influenciar positivamente a organização do trabalho e favorecer a construção de objetivos comuns, intensificando a articulação entre os profissionais e a atuação da equipe multiprofissional Santos et al. (2016). Subcategoria II Falta de recursos humanos e materiais: Os profissionais demonstram que o ambiente do CC é limitado justamente pela falta de recursos, sejam eles materiais ou humanos. O enfermeiro vivencia a sobrecarga de trabalho, a limitação dos recursos humanos e materiais, podendo dessa maneira resultar em erros durante o processo de trabalho, redução da produtividade, além de desentendimento entre com equipe do CC, portanto é importante que o enfermeiro saiba lidar com a gestão de estresse. Ainda, existem grandes desafios na área de recursos humanos de enfermagem e das condições dos ambientes de prática em hospitais brasileiros para alcançar um cuidado de saúde seguro Magalhães et al. (2015). Categoria III Tomada de decisão frente aos conflitos éticos: O enfermeiro depara-se com constantes conflitos do qual exige dos mesmos uma tomada de decisão. Devem ser levados em consideração a opinião da equipe multidisciplinar para resolução dos conflitos, buscando o bem estar do paciente e da equipe do $\mathrm{CC}$, bem como seguir os princípios éticos para a tomada de decisão. Subcategoria I Opinião da equipe multiprofissional: Os profissionais relatam que tomam decisões em conjunto com a equipe do $\mathrm{CC}$, buscando a melhor forma para resolver os conflitos que surgem no CC, buscando a decisão mais assertiva possível, onde sejam atendidos os diversos interesses. O enfermeiro é visto como o profissional que propicia a comunicação entre a equipe, facilitando o cuidado integral ao paciente proporcionando o atendimento das necessidades que requerem solução compartilhada com a equipe multidisciplinar Negreiros et al. (2017). Subcategoria II Procurar o bem estar da equipe cirúrgica e do paciente: Os enfermeiros demonstram que é essencial procurar o bem estar de ambos tanto do paciente quanto do profissional da equipe multidisciplinar, sendo imprescindível que esses profissionais tenham condições de trabalho e de saúde para atender bem ao paciente que necessita de seus cuidados. De acordo com Maurício (2017) e demais colaboradores atualmente há evidências na literatura mundial referente aos benefícios do trabalho em equipe como instrumento fundamental para a manutenção da qualidade nos serviços de saúde. Subcategoria III - Observar os princípios éticos: Os enfermeiros relatam a importância de levar em consideração os princípios éticos e os princípios da bioética para a tomada de decisão, buscando sempre agir de maneira ética. A tomada de decisão necessita ser cautelosa, ponderada e criteriosa respeitando os princípios éticos para que as decisões sejam a mais assertiva e traga benefícios ao paciente, sendo essencial o respeito e a responsabilidade no agir do profissional. Para a resolução de conflitos, a análise ética dos fatos relacionados se faz necessária, além do conhecimento das teorias éticas, que direcionam e sistematizam a tomada de decisão. Araújo \& Massarollo (2014). Subcategoria IV Observação e Reflexão na tomada de decisão: O profissional relata que a tomada de decisão necessita de observação e reflexão para que a melhor alternativa seja escolhida. A comunicação é essencial na tomada de decisão e no gerenciamento do cuidado, requerendo integração entre a equipe do $\mathrm{CC}$, auxiliando especialmente, no que tange à resolução e minimização dos problemas de saúde. O estresse é vivenciado principalmente entre os profissionais da equipe do CC, por se tratar de um ambiente que requer uma tomada de decisão mediante as situações complexas e cujo tempo é limitado para a análise das 
alternativas diferentes a ser escolhida. A reflexão sobre responsabilidade e competência estabelece um instrumento norteador para a tomada de decisões com base em normas legais e princípios éticos profissionais Fontoura et al. (2011).

\section{CONSIDERAÇÕES FINAIS}

Esta investigação permitiu conhecer a postura do enfermeiro frente aos conflitos éticos vivenciados no $\mathrm{CC}$, e possibilitou a compreensão de situações que necessite de uma deliberação, ajudando na escolha de posturas éticas e no desenvolvimento das habilidades para a tomada de decisão. A pesquisa apontou que os enfermeiros vivenciam constantemente na sua prática os conflitos éticos que surgem decorrentes a divergências entre profissionais do $\mathrm{CC}$, escassez de recursos humanos e materiais e a sobrecarga de trabalho. Os enfermeiros compreendem conflitos quando existe uma situação, com alternativas diferentes, na qual fazse necessário a tomada de decisão. A tomada de decisão diante de conflitos deve ser em comum acordo com a equipe multiprofissional, isto é, por meio da integração entre seus componentes, decidindo em conjunto levando em consideração os interesses tanto da equipe de CC, quanto do paciente. Assim, a comunicação e a integração devem estar presentes para que a decisão escolhida seja coerente e eficaz. As facilidades na realização da pesquisa foi o bom relacionamento com a equipe do CC. A dificuldade enfrentada foi a falta de disponibilidade dos enfermeiros devido as atividades do $\mathrm{CC}$, que dificultou a coleta de dados.

\section{REFERÊNCIAS}

ARAÚJO, Mara Nogueira de; MASSAROLLO, Maria Cristina Komatsu Braga. Conflitos éticos vivenciados por enfermeiros no processo de doação de órgãos. Acta Paulista de Enfermagem, São Paulo. 27(3):215-20, 2014.

BARDIN, L. Análise de conteúdo. São Paulo: Edições 70, 2011.

BRASIL. Ministério da Saúde. Resolução CNS 466/12. Conselho Nacional de Saúde. Comissão Nacional de Ética e Pesquisa com Seres Humanos. 2012.

BRUINSMA, Jamile Lais et al., Conflitos entre idosas institucionalizadas: dificuldades vivenciadas pelos profissionais de enfermagem. Escola Anna Nery revista de enfermagem, Rio de Janeiro. 21(1): e20170020, 2017.

FIGUEIREDO, Antonio M. Ética: origens e distinção da moral. Rev. USP Saúde, Ética e Justiça. v.13 n.1. p.1-9. 2008.

FONTOURA, Elaine Guedes. et al. Processo de formação da enfermeira para um agir ético. Revista Baiana de Enfermagem, Salvador, v. 25, n. 1, p. 59-68, jan./abr. 2011.

LACERDA, C. N. A ética nas relações de trabalho entre os profissionais de enfermagem. Rev. Brasileira de Educação e Saúde, v. 4,n. 4, p. 18-24, out.-dez., 2014.

MAURÍCIO, Luiz Felipe Sales. Prática profissional do enfermeiro em unidades críticas: avaliação das características do ambiente de trabalho. Revista Latino Americana de Enfermagem, Ribeirão Preto. 25:e2854, 2017.

MAGALHÃES, Ana Maria Müller de. Grau de dependência de pacientes em unidade de internação cirúrgica. Revista Brasileira de Enfermagem, Brasília. 68(5):824-9. set/out, 2015.

NEGREIROS, Francisca Diana da Silva et al., Percepção da equipe multiprofisssional sobre as competências do enfermeiro no transplante hepático. Revista Brasileira de Enfermagem, Brasília; 70(2):258-64, mar/abr, 2017.

OLIVEIRA, Marluce Alves Nunes; SANTA ROSA, Darci Oliveira. Método de análise de problemas morais aplicado à prática da enfermagem. Feira de Santana: UEFS Editora, 2014. $184 \mathrm{p}$.

SANTOS, José Luís Guedes dos et al., Estratégias utilizadas pelos enfermeiros para promover o trabalho em equipe em um serviço de emergência. Revista Gaúcha Enfermagem, Rio Grande do Sul. 37(1):e50178, mar. 2016. 